\title{
Economic Aspects of Quality of Life of Bangladeshi Construction Workers in Malaysia
}

\author{
Md Wahidul Haque \\ $\mathrm{PhD}$ candidate \\ Faculty of Applied Social Science \\ University Sultan Zainal Abedin \\ Terengganu, Malaysia \\ Tel:601160828424Ｅ-mail: wahidorion5155@gmail.com
}

\author{
Norizan Abdul Ghani (Corresponding author) \\ Professor in the Faculty of Applied Social Science \\ University Sultan Zainal Abedin \\ Terengganu, Malaysia
}

Tel: 60199149192 E-mail: norizabd@unisza.edu.my

Received: March 22, 2020 Accepted: April 5, 2020 Published: April 13, 2020

doi:10.5296/jad.v6i1.16725 URL: https://doi.org/10.5296/jad.v6i1.16725

\begin{abstract}
Quality of Life (QoL) measures provide a sense of how people's lives are going through the activities and interactions between their circumstances and psychological resources. This measurement/ evaluation is a valuable tool and a precondition for planning to improve the socio-economic QoL or Wellbeing of the people surveyed. Researchers conducted a qualitative study to know the economic QoL of Bangladeshi migrant construction workers in Terengganu, who have immigrated for less than ten years in Malaysia. Researchers triangulated the survey by two focus group discussions, 19 in-depth interviews, and observations of four spots. The research used Atlas ti to conduct the thematic analysis of the primary data. The result of the study shows that the workers are mostly in adverse QoL with the effect of freedom, functioning, facilitator, and financial management. The study finally recommends, Community-based work permit, trade union, and digital financial system to
\end{abstract}


ensure more freedom to improve the economic QoL of the migrant Bangladeshi construction workers.

Keywords: Migrant worker, Freedom, Quality of Life

\section{Introduction}

Quality of life (QoL) is individuals' perception of their position in the context of the culture and value system in which they live and their goal, expectation, standard, and concern (WHO, 1996). Subjective QoL (SQoL), on the other hand, provides a sense of how lives are going, through the activities and interaction between their circumstances and psychological resources (New Economics Foundation, 2018). SQoL measurements are continually being refined, as the concept is becoming increasingly important (McCabe and Johnson, 2013). This measurement/ evaluation is a valuable tool and a precondition for planning to improve the socio-economic QoL of the people surveyed. The researchers synonymously use subjective QoL and Wellbeing, so the same approach is adopted in this article.

Different counties around the globe, measure QoL or Wellbeing with different domains and indicators customized for them. The Canadian Index of Wellbeing (CIW) consists of eight fields, each again with eight various indicators (Smale \& Hilbrecht, 2017). Twenty-nine countries of the European Union (EU) use subjective measures of QoL, focusing on life satisfaction. United Kingdom (UK) and 34 Organization for Economic Co-operation and Development (OECD) countries also measure QoL focusing on life satisfaction but with a different set of indicators. Australian concept (Bache et al., 2016) of QoL is again different than others.

While assessing the QoL, developed nations also focus separately on migrants, but that is mostly on permanent residents, not the temporary workers. Even though some research work and literature found on temporary workers' QoL in developed nations like the UK, the USA, and Australia. Amongst those, some concentration is also found on Bangladeshi migrant workers in those countries. Few researches were found focusing on Bangladeshi migrant workers in Malaysia but barely talked about the QoL as a whole. Researchers focused on Adaptability (Rokis \& Basir, 2017), Sending Remittance (Rokis \& Basir, 2017), Discrimination Against Migrant Workers in Malaysia (Ayub et al., 2016), Migrant Workers and Good Governance in Malaysia (Rahim, 2015), Health Seeking Behavior (Karim \& Diah, 2015), Socio-Economic Condition (Rahman et al., 2014), Survival Strategy (Sultana Nayeem, 2008), Transnational Identities in Multicultural Context (Sultana Nayeem, 2008). This article mainly highlights the qualitative part of doctoral research on the QoL of temporary migrant Bangladeshi workers in Malaysia. Economic QoL of the Bangladeshi workers staying for less than ten years in Malaysia is the only focus of this article.

\section{Methodology}

This qualitative study on the economic aspects of QoL of temporary immigrant Bangladeshi construction workers was conducted in Terengganu, east coast of Malaysia. A wide variety of globally used social indicators of QoL like Canadian Index of Wellbeing (CIW), United Nations Human Development Index (UNHDI), Australian concept, and Organization for Economic Cooperation for Development (OECD) were consulted and the gross indicators were initially selected. Then basing on those indicators, two focused group discussions (FGD) 


\section{MInstitute ${ }^{\text {Macrothink }}$}

were conducted to suit index as per the situation of the migrant construction workers. One FGD took place in the construction site of the under-construction UniSZA hospital complex at Gong Badak, and the other was in the accommodation of construction workers at Marang, Terengganu. Basing on the indicators selected from the secondary sources and the outcome of the FGDs, open ended and semi structured questions were prepared for in-depth interview. Researchers conducted a multilevel in-depth interview of 12 construction workers, two Bangladeshi embassy officials, two visa agents and three intellectuals following data saturation technique. Two FGDs, 19 in-depth interviews, and observations of four living areas triangulated the research. The study also used secondary source on the studies conducted on temporary Bangladeshi immigrant workers in Malaysia. Upon collecting the qualitative data thematic analysis using atlas ti was conducted and interpreted in line with the research objectives. The study is limited to the temporary migrant Bangladeshi construction workers staying for less than ten years in Malaysia.

\section{Literature Review}

\subsection{Subjective $Q o L$}

Subjective QoL measures provide "a sense of how (people's) lives are going, through the activities and interaction between their circumstances and psychological resources" (New Economics Foundation, 2018). The QoL is generally a subjectively assessed multi-dimensional tool (Organization for Economic Cooperation, 2013). Since 2008, as the Sarkozy Stieglitz Commission recommended adding up new metrics to measure societal Wellbeing as an indicator of progress, significant follow-up activity has been taken up by most governmental bodies around the globe (Krueger A, 2014). The subjective approach assumes that what constitutes 'good' and 'quality' are embedded in the context of personal goals, talents, values, histories, and life experiences (New Economics Foundation, 2018). This subjective approach accepts that QoL is a dynamic interaction between the external conditions of an individual's life and the internal perceptions of those conditions.

\subsection{Kaleidoscope and Present-day Context of Migration}

In the early 1990s, Malaysia needed a high number of workers to carry out its construction work and industrialization activities, Bangladeshi migrant workers started coming since then. Because like many other countries, labor migration is a source of employment in Bangladesh (Wickramasekara, 2016). The Iraq-Kuwait crises in 1990-91 also influenced the shift from that region to South-East and East Asia (Abdul-Aziz, 2001). Since Malaysia was in a dire shortage of workforce, it agreed in 1992 with Bangladesh "for a large scale systematic transfer of labor" (Abdul-Aziz, 2001). Bangladeshi workers constituted the second-largest workforce in Malaysia during that period. Two main factors (P. Iruthayaraj D Pappusamy, 2014) of attracting migrant workers in Malaysia are: (i) Malaysia offers higher wages and opportunities compared to workers' home state. (ii) There are lots of opportunities for foreign workers to work in the 3D sector (dangerous, dirty, and painful) of construction, plantation, agricultural, and manufacturing industries.

The number of foreign workers in Malaysia is rising to whooping seven million, which is $22.1 \%$ of the total population of 31.7 million (Wong Chun Wai, 2016). As the figure shows, at the end of September 2016, the country had 1.85 million foreign workers with temporary 


\section{MInstitute ${ }^{\text {Mink }}$}

employment pass. This figure did not include undocumented workers. Of the total, Indonesia accounted for $40 \%$, Nepal second with $22 \%$, and Bangladesh third with $13 \%$. The Malaysian Employers Federation (MEF) estimated that six million documented and undocumented foreign workers are working mainly in the labor-intensive construction, manufacturing, and plantation sectors (Tan Heng Hong, 2017).

\subsection{Low $Q o L$}

Though remittance helps family back home in multi-dimensional ways, e.g., changing financial conditions, paying debt, increase in savings (Rahman et al., 2014). Still, the workers lead a low QoL with a lot of sufferings in Malaysia. Some of these sufferings are due to mismatch in their qualification, language, culture, dishonest workforce agents, accidents in the workplace, poor housing, acceptance by the people of receiving countries, and others (Kanapathy, V., 2007; Rahman, Uddin, \& Albaity, 2014). Workers usually share a room, which is often congested and unhealthy. Five Bangladeshi workers are living in one single apartment without any ventilation, which could roughly be measured 200 sq. Feet, where they cook, dine, and sleep together (Zehadul Karim et al., 2015).

Bangladeshi recruiting agents exploit and cheat the workers in many ways. They don't make any agreement with the Malaysian employer directly; instead, they contact a Malaysian agent (who is again mostly a greedy and corrupt Bangladeshi, staying for a long time and some of them married to local Malay lady) of the employer. Bangladeshi agents and sub-agents cheat the workers with the false promise of earning Malaysian Ringgit ${ }^{1}$ (RM) 2,500 to 3,000/ month with free accommodation in the right living conditions, treatment facilities, and insurance.

Three violations and bindings of Malaysian law are pushing the QoL of Bangladeshi workers down. Firstly, in employing a migrant worker, employers have to bear levies. In most of the cases in the construction sector, employers do not pay the levies but deducted from workers' wages (Huling, 2012). Secondly, migrant workers cannot take part in any trade unions or other labor organizations to protest any unjust (Yamada, 2015). Thirdly, the Malaysian Govt does not allow a migrant worker to have a choice of changing the employer. If someone cannot continue, due to adverse working conditions, less salary, illness, or misconduct, they cannot stay in Malaysia legally, they become undocumented and suffer a low QoL.

\section{Findings}

\subsection{Facilitator of Migration and Migrants}

Instead of having a direct relation with employer and worker, there are three more layers of middlemen in the chain of recruitment and employment (as shown in figure 1). When the employer is in need, they ask the Malaysian agent; in turn, they ask their Bangladeshi counterpart. Another layer of Bangladeshi sub-agent connects workers in this whole process. These groups of people in between employer and employee suck the blood and pump out the finance from the workers. Two layers in the Bangladesh side have only one chance to exploit by creating an 'opportunity trap', and they take up to RM 20,000 (R-3) from each individual, whereas the Govt rate is only RM 3,000 (R-7). So, almost seven times, extortion is going on.

Bangladeshi Embassy in Malaysia, being a facilitator agency in the destination country, cannot again help the workers to the required extent because of a lot of extra pressure of

\footnotetext{
${ }^{1}$ USD 1 is equivalent to 4.40 Malaysia Ringgit
} 
undocumented workers (R-6). The Bangladeshi High Commission has extended its passport office activities because of this extra pressure. Additional Govt employees of Bangladeshi passport office temporarily come to Malaysia. The chief of the team Rahman (false name) reported that "We came to Malaysia temporarily just to stabilize the pressure of issuing new and renew old passport (R-11)." So, pursuing labor wing facilitator activities like communicating with workers and employers, market survey, placement of workers, looking after welfare, managing compensation package remains a far cry. There is a small role of an embassy to play in the chain of employer agents and employees (R-4).

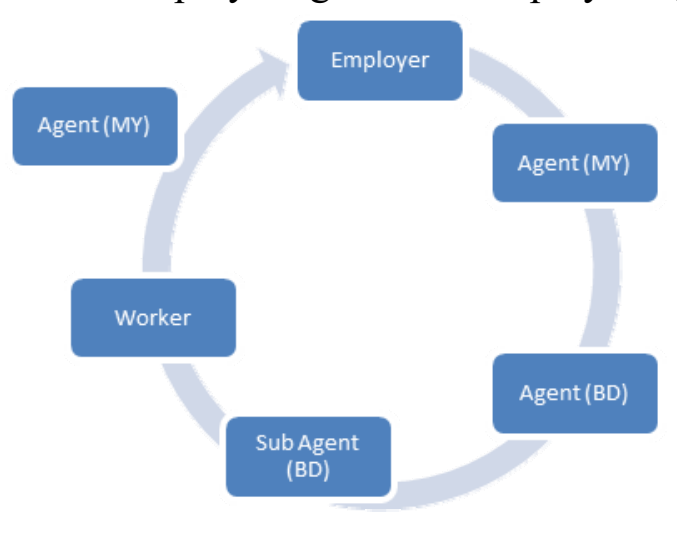

Figure 1. Chain of Recruitment and Employment

Source: Researcher's Concept from Field Study

\subsection{Functioning; Attraction Towards Construction Sector}

Many of the workers in the construction sector did not migrate as a construction worker. Many undocumented migrants choose this sector, and many documented migrants workers dive in as undocumented and join this sector for several reasons. High income is one of the major attractions of this sector (R-3). In general, a worker earns RM 50 /day and can manage up to two hours of overtime, which adds up another RM 15. If everything goes well, RM 65 in 25 days makes RM 1625 /month. But the fact of regular payments remains as a big question. Many have reported getting the salary with a gap of two to two and a half months. Choice from a variety of trades like masonry, electrical, sanitation, tiles work, painting, and welding is also another reason to join the construction sector. In these specialized sectors, workers can earn RM 75 to 95/ day as basic, basing on the work capacity, and it goes up to even RM 110. To achieve these level people takes about eight to nine years. So, altogether it makes RM 1,850 to RM 2750 in a month and makes a big difference at the end. Forming a team under a supervisor and managing subcontract is also a reason for choosing this sector.

\subsection{Financial Management; High Earning, High Spending, and no Saving}

None of the respondents, who came after 2012 (for the last seven years), could save any money, other than one. In most cases, initial three to four years is gone to pay back the loans taken for migration, and five to seven years is spent to get a stable foothold in this foreign land. Though the income ratio is much higher in Malaysia, almost three times in comparison to Bangladesh (R-6), the expenditure ration is also very high. Generally, people are spending RM 400 for their 


\section{MInstitute Macrothink $^{\text {Int }}$}

own expense, which is unthinkable in Bangladesh. Even with this money, a family could run. Again, they need to spear approximately RM 400 per month for the work permit, RM 500 for repaying the loan (initial three-four years). Family expenses are around RM 400/ month, and altogether they spend up to RM 1,700 (in most cases, younger workers are unmarried, so they do not spend for the family, and they decide to marry after spending initial four years of repaying the loan). So, almost there is no wealth creation or saving for almost initial seven years. Family expenditure is also more than doubled (R-8) because of improving family status, sending children to better school/place, and spending without his supervision (in many cases, the wife becomes the decision-maker of spending).

\subsection{Freedom}

Malaysian agents sometimes act in a duel role of employer and visa agent in the construction sector because they can manage subcontracts from the main contractor (R-8). This group of people continues to pump out workers' earning and keep them poor, financially, and mentally for the initial three to four years (R-9). These employer cum agents in one hand deduct 1800 $\mathrm{RM}$ for levies and also charge RM 2,000 to 2,200 as processing cost (R-9). This hidden processing cost is the major cause of low QoL perception. For avoiding very high processing costs along with the cost of levies, many of the workers become undocumented (R-3), losing all freedom stepping in a 'freedom trap'. Once the Malaysian Govt opens up the legalization process, most of them want to be documented and stay for another ten years, legally. This time also the agents charge very high, approximately RM 9,000 to RM 10,000 (R-2). Figure 2 shows a dark way of financial exploitation that begins in Bangladesh and continues through the initial period of instability. Finally, after getting settled, this exploitation ends.

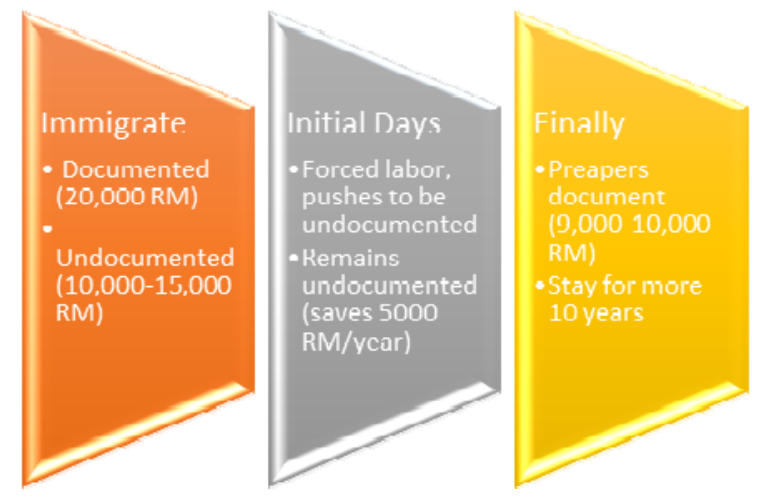

Figure: 2 Dark Subway of Undocumented Workers

Source: Researcher's Concept from Field Study

\section{Discussion}

A trade union is an essential mechanism for a worker to exercise collective bargaining power with the employer (Suraya et al., 2019). Presently, the Malaysian Govt put some indirect barriers to trade unions, but it is a significant indicator of a developed nation. As Malaysia is expecting to enter the list of a developed nation by 2020, she needs to open the bindings of the labor union. Malaysian Govt should establish an independent administrative trade union board and ratify the convention concerning Freedom of Association and protection of the right to organize convention No. 87 (Suraya et al., 2019). The trade union will enable Bangladeshi 
deprived workers to create pressure on the employer against their misconduct and violations.

Social protection and QoL of migrant workers can be enforced by promoting ILO ratification and recommendation, implement the of the bilateral agreement, promote the inclusion of social security provisions by exploring community-based mechanisms (Khan, 2017). Mojlish is a well-established community-based welfare program that can be the right approach for ensuring freedom of immigrant workers if the trade union is not fully functional. By amending the law, if a Mojlish of the local community can process levies, then exploitation of the agent cum employer could be stopped. Volunteer service of three/four hours a week by those enrolled under Mojlish will benefit the local community. Workers, on the one hand, would love to pay RM 1,800 as levies from their own earning and can save RM 2,200 as processing cost, local community, on the other hand, can get volunteer service of RM 30,000 from 1000 workers registered under that. By implementing this community- based approach, a win-win situation can prevail, and QoL of Bangladeshi workers may drastically improve by achieving freedom.

Workers should have a bank account and should be paid directly to the account. Present days workers even less educated can manage internet and mobile banking because they are familiar with Facebook and can communicate in social media (R-8). Every month RM 150 may be deducted from their direction, which will make RM 1800 in a year for Govt payment (R-7). Every month RM 150 will not be a significant burden for the worker. They will also be able to send remittance directly from that account without traveling to money, sending vendors every weekend spoiling a lot of time and money. Presently, the deprived or the cheated workers cannot do anything against the employer because of the lack of proof. This account will bear evidence of receiving a salary from the employer, and the workers will also be able to prove their financial transactions.

\section{Conclusion}

The contribution of Bangladeshi migrant construction workers to Malaysia's infrastructural development is significant. Therefore, a deeper understanding of Bangladeshi migrant workers' economic life in Malaysia may significantly help both governments to take action to improve their QoL. Improved QoL will assist workers in providing better service to Malaysia and a more significant contribution to their economy back home. Forced labor, lack of freedom, lack of facilitators' initiative, and financial management are the leading causes of low QoL of Bangladeshi workers. Opening up a trade union, Mojlish/ community-based levies, and digital financial management system might improve the QoL situation of them.

\section{Acknowledgments}

Thanks to Dr. Norizan for supervising the research.

\section{References}

Abdul-Aziz, A. R. (2001). Bangladeshi Migrant workers in Malaysia's Construction Sector. Asia Pacific Population, 16(1), 3-22. https://doi.org/10.18356/e085943a-en

Ayub, Z. A., Yusoff, Z. M., \& Wahab, H. A. (2016). Discrimination Against Migrant Workers In Malaysia (Issue October 2017). https://doi.org/10.22146/jmh.16692 
Bache, I., Reardon, L., \& Anand, P. (2016). Wellbeing as a Wicked Problem: Navigating the Arguments for the Role of Government. Journal of Happiness Studies, 17(3), 893-912. https://doi.org/10.1007/s10902-015-9623-y

Cooperation, O. for E. (2013). How's life? 2013: measuring well-being. OECD Publishing.

Foundation, N. E. (2018). National accounts of well-being: bringing real wealth onto the balance sheet. In New Economics Foundation Publishing.

Huling, A. (2012). Domestic Workers in Malaysia: Hidden Victims of Abuse and Forced Labor. International Law and Politics, 44, 629-680.

Karim, A. H. M. Z., \& Diah, N. M. (2015). Health Seeking Behavior of the Bangladeshi Migrant Workers in Malaysia: Some Suggestive Recommendations in Adjustive Context. Asian Social Science, 11(10). https://doi.org/10.5539/ass.v11n10p348

Khan, R. S. (2017). Social Protection of Migrant Workers. International Migration Day Journal, 1(2017), 45.

Krueger, A. S. A. (2014). Progress in measuring subjective well-being. Science, 346(6205), 42-43. https://doi.org/10.1126/science.1256392

Palma, P. (2009, April 11). Shattered Dreams Of Migrant Workers -6exploitation Of Bangladeshis In Malaysia $\mathrm{Hr}$ activist terms it human trafficking. The Daily Star. https://www.thedailystar.net/news-detail-83694

Rahim, R. A. (2015). Migrant workers and good governance in malaysia. November.

Rahman, M., Uddin, S. J., \& Albaity, M. (2014). Socio-economic Conditions of Bangladeshi Migrant Workers in Malaysia. 4(3), 246-252.

Rokis, R., \& Basir, N. (2017). Roles and Social Adaptability of Bangladeshi Migrant Workers in Commercialised Farming of Cameron Highlands, Malaysia. September.

Smale, B., \& Hilbrecht, M. (2017). From National to Local: Measuring Well-Being at the Community Level (pp. 293-312). https://doi.org/10.1007/978-94-024-0878-2_16

Sultana Nayeem, G. S. (2008). Inter-Ethnic Marital Practice of Bangladeshi Diaspora - An Example of Diaspora Adaptation at this Age of Globalization. Journal of Identity and Migration Studies, 2(1), 57-81. http://www.e-migration.ro/jims/Vol2_no1_2008/JIMS_vol2_no1_2008_Sultana_Gerke.pdf

Suraya, S., Razak, A., Ahmad, N., \& Nik, K. (2019). Trade Union Recognition in Malaysia: Legal Issues. July 2018.

Tan Heng Hong. (2017). A visit to a sundry shop catering to Bangladeshi in Kuala Lumpur Mini Me Insights. Minime Insights. https:/www.minimeinsights.com/2017/03/25/visiting-sundry-shops-catering-to-bangladeshi-i n-kuala-lumpur/

WHO. (1996). Introduction, administration, scoring and generic version of the assessment 


\section{Macrothink}

programme on mental health world health organization. December.

Wickramasekara, P. (2016). Review of the government-to-government mechanism for the employment of Bangladeshi workers in the Malaysian plantation sector (Issue February).

Wong Chun Wai. (2016). Rising number of foreign workers in Malaysia - a worrying statistic: The Star columnist, SE Asia News \&amp; Top Stories - The Straits Times. The Straits Times. http://www.straitstimes.com/asia/se-asia/should-we-think-about-malaysia-the-star-columnist

Yamada, N. (2015). Migrant Workers as a Peripherality : Advocacy and Organizing Activities. September.

Zehadul Karim, A. H. M., Mohamad Diah, N., Mustari, S., \& Islam Sarker, S. (2015). Bangladeshi Migrant Workers in Malaysia: Their Socio-Cultural Background and Work-Adaptability. South Asian Anthropologist, 15(1), 1-7. http://serialsjournals.com/serialjournalmanager/pdf/1470649262.pdf

\section{Glossary}

QoL: Quality of Life

SQoL: Subjective Quality of Life

CIW: Canadian Index of Wellbeing

EU: European Union

UK: United Kingdom

OECD: Economic Co-operation and Development

ILO: International Labor Organization

RM: Ringgit Malaysian (Malaysian Currency)

\section{Copyright Disclaimer}

Copyright for this article is retained by the author(s), with first publication rights granted to the journal.

This is an open-access article distributed under the terms and conditions of the Creative Commons Attribution license (http://creativecommons.org/licenses/by/4.0/). 